\title{
The adsorption of benzene and methylethylketone onto activated carbon: thermodynamic aspects
}

\author{
H.L. Chiang ${ }^{\text {a }}$, C.P. Huang ${ }^{\text {b,* }}$, P.C. Chiang ${ }^{c}$ \\ a Department of Environmental Engineering, Fooyin Institute of Technology, 151 Chin-Hsueh Road, \\ Ta-Liao Hsiang, Kaoshsiung Hsien, 831, Taiwan, ROC \\ ${ }^{\mathrm{b}}$ Department of Civil and Environmental Engineering, University of Delaware, Newark, DE 19716, USA \\ ${ }^{\mathrm{c}}$ Graduate Institute of Environmental Engineering, National Taiwan University, 71 Chou-Shan Road, Taipei, Taiwan, ROC
}

Accepted 4 August 2000

\begin{abstract}
The adsorption of volatile organic compounds (VOCs), exemplified by benzene and methylethylketone (MEK), onto seven different types of activated carbon was investigated. Results show that for benzene adsorption the adsorption characteristic energy, enthalpy, free energy and entropy are in the range $17.12-36.86,-20.8$ to $-44.7,-11.89$ to -16.22 $\mathrm{kJ} / \mathrm{mole}$ and -29.4 to $-85.3 \mathrm{~J} / \mathrm{mole} / \mathrm{K}$, respectively. For the adsorption of MEK, the adsorption characteristic energy, enthalpy, free energy and entropy are in the range $14.47-32.34,-18.3$ to $-40.8,-10.78$ to $-15.56 \mathrm{~kJ} / \mathrm{mole}$ and $-24.8 \sim-60.3 \mathrm{~J} / \mathrm{mole} / \mathrm{K}$, respectively. The adsorption enthalpy can be calculated indirectly from statistical thermodynamic method and directly from the immersion enthalpy method. The adsorption characteristic energy is calculated by the Dubinin-Astokhov equation. The free energy is calculated by the measured equilibrium adsorption constant. (c) 2001 Elsevier Science Ltd. All rights reserved.
\end{abstract}

Keywords: VOCs; Adsorption; Activated carbon; Thermodynamics

\section{Introduction}

Activated carbon is a porous carbonaceous material and has been extensively used in many industrial applications (Koresh and Sofer, 1983; Hassan et al., 1987; Ruthven et al., 1987; Grunewald and Drago, 1990). It has found common uses in air purification, volatile solvent recovery, deodorization, and drinking water treatment (McDowell, 1961; Cheremisinoff and Ellerbusch, 1978). Activated carbon has also been used as a catalyst and catalyst support by the chemical industry (Trapnell, 1955).

Better understanding of the thermodynamic aspects of the adsorption reaction can aid in the design of ac-

\footnotetext{
${ }^{*}$ Corresponding author. Tel.: +1-302-831-8428; fax: +1-302$831-3640$.

E-mail address: huang@ce.udel.edu (C.P. Huang).
}

tivated carbon adsorption process. As far as adsorption volatile organic compounds (VOCs) at the activated carbon-water interface is concerned, much has been reported on the determination of free energy of adsorption. However, very little is known about the entropy and the enthalpy of adsorption between VOCs and activated carbon. Moreover, the distribution energy on the activated carbon surface remains a subject of little attention.

Dubinin et al. (1991) by applying the DubininRaduskevich equation, i.e., theory of micropore volume filling (TVFM), have determined the adsorption energy of ethylene, benzene, carbon tetrachloride on activated carbon. Based on the Dubinin theory, Stoeckli and Kraehenbueh (1981) have established the relationship between the enthalpy of immersion and some parameters of TVFM for the adsorption of benzene, $n$-heptane and water onto activated carbon. However the TVFM theory can not sustinctly determine the free energy and 
entropy of adsorption. Afzal et al. (1993) have used the adsorption data and a virial isotherm to calculate the enthalpy, entropy and free energy of the adsorption of methanol, acetone, methyl formate and acetaldehyde by activated carbon. However, they have not succeeded in determining the relevant thermodynamic parameters. This study is to determine the thermodynamic properties and the energy distribution function of the adsorption of VOCs by activated carbon exemplified by benzene and methylethylketone (MEK). Both immersion enthalpy method and statistical thermodynamic method (for entropy calculation) were used.

\section{Theoretical aspects}

\subsection{Immersion enthalpy method}

According to Dubinin, the net heat of adsorption $\left(q^{\text {net }}\right)$ is the difference between the isoteric heat of adsorption $\left(q^{\mathrm{st}}\right)$ and the heat of condensation $\left(\Delta H_{\mathrm{con}}\right)$, that is,

$q^{\text {net }}=q^{\text {st }}-\Delta H_{\text {con }}$.

The adsorption isoteric heat can be estimated by the following equation (Smisek and Cerny, 1970; Gregg and Sing, 1982)

$q^{\text {net }}=R T^{2}\left(\frac{\partial \ln x}{\partial T}\right)_{a}$,

where $x$ is the relative pressure, $p / p_{0}$, and is related to the Gibbs equation, that is,

$\Delta G=-R T \ln x=-R T \ln \frac{p}{p_{0}}$,

where $p_{0}$ is the saturation vapor pressure and $p$ is the equilibrium vapor pressure.

By definition,

$a \tilde{v}=W$,

where $W$ is the volume of adsorption space, $a$ is the number of moles adsorbed and $\tilde{v}$ is the molar volume of adsorbed material.

According to the potential theory, $W$ is a function of $T$ and $x$, that is,

$W=f(T ; \ln x)=a \tilde{v}$.

Taking a total differentiation of Eq. (4), one has

$\mathrm{d}(a \tilde{v})=\left(\frac{\partial a \tilde{v}}{\partial T}\right)_{\ln x} \mathrm{~d} T+\left(\frac{\partial a \tilde{v}}{\partial \ln x}\right)_{T} \mathrm{~d} \ln x$.

Diving all terms in Eq. (5) by $T$ at equilibrium and since $\mathrm{d}(a \tilde{v})=0$, one has

$$
\left(\frac{\partial a \tilde{v}}{\partial T}\right)_{\ln x}=-\tilde{v}\left(\frac{\partial a}{\partial \ln x}\right)_{T}\left(\frac{\partial \ln x}{\partial T}\right)_{a \tilde{v}}
$$

or

$\left(\frac{\partial a \tilde{v}}{\partial T}\right)_{\ln x}=-\tilde{v}\left(\frac{\partial \tilde{v}}{\partial \ln x}\right)_{T}\left(\frac{\partial \ln x}{\partial T}\right)_{a \tilde{v}}$.

The coefficient $\left(\partial a \tilde{v} / \partial T_{\ln x}\right)$ can also be expressed as

$\left(\frac{\partial a \tilde{v}}{\partial T}\right)_{\ln x}=a\left(\frac{\partial \tilde{v}}{\partial T}\right)_{\ln x}+\tilde{v}\left(\frac{\partial a}{\partial T}\right)_{\ln x}$.

By defining $\alpha$ as the thermal coefficient of volume expansion and $\alpha$ is equal to $1 / \tilde{v}(\partial \tilde{v} / \partial T)_{\ln x}$. Eq. (7) becomes

$\left(\frac{\partial a \tilde{v}}{\partial T}\right)_{\ln x}=a \alpha \tilde{v}+\tilde{v}\left(\frac{\partial a}{\partial T}\right)_{\ln x}$.

Combining Eqs. (6b) and (8) yields the following expression

$a \alpha \tilde{v}+\tilde{v}\left(\frac{\partial a}{\partial T}\right)_{\ln x}=-\tilde{v}\left(\frac{\partial a}{\partial \ln x}\right)_{T}\left(\frac{\partial \ln x}{\partial T}\right)_{a \tilde{v}}$.

Rearranging Eq. (9a) one has

$\left(\frac{\partial a}{\partial T}\right)_{\ln x}=-\left(\frac{\partial a}{\partial \ln x}\right)_{T}\left(\frac{\partial \ln x}{\partial T}\right)_{a \tilde{v}}-a \alpha$.

According to the potential theory, $\Delta G$ is independent of the temperature, so we can have following relationship

$\left(\frac{\partial \Delta G}{\partial T}\right)_{a \tilde{v}}=-R T \ln x-R\left(\frac{\partial T \ln x}{\partial T}\right)_{a \tilde{v}}=0$

or

$\left(\frac{\partial \ln x}{\partial T}\right)_{a \tilde{v}}=-\frac{\ln x}{T}$.

By substituting Eq (10b) into Eq. (9b), it yields

$\left(\frac{\partial a}{\partial T}\right)_{\ln x}=\left(\frac{\partial \ln a}{\partial \ln x}\right)_{T} \frac{\ln x}{T}-a \alpha$.

Expressing $a$ as a function of $T$ and $\ln (x)$, one has

$\mathrm{d} a=\left(\frac{\partial a}{\partial T}\right)_{\ln x} \mathrm{~d} T+\left(\frac{\partial a}{\partial \ln x}\right)_{T} \mathrm{~d} \ln x=0$.

Rearranging Eq. (12a) yields

$\left(\frac{\partial a}{\partial T}\right)_{\ln X}=-\left(\frac{\partial a}{\partial \ln X}\right)_{T}\left(\frac{\partial \ln X}{\partial T}\right)_{a}=0$. 
By substituting Eq. (12b) into Eq. (11), one has

$-\left(\frac{\partial a}{\partial \ln x}\right)_{T}\left(\frac{\partial \ln x}{\partial T}\right)_{a}=\left(\frac{\partial a}{\partial \ln x}\right)_{T} \frac{\ln x}{T}-\alpha a$.

Rearranging Eq. (13a) yields

$\left(\frac{\partial \ln x}{\partial T}\right)_{a}=-\frac{\ln x}{T}+\alpha\left(\frac{\partial \ln x}{\ln a}\right)_{T}$.

By substituting Eq. (13b) into Eq. (2), and after rearrangement, one has

$q^{\text {net }}=R T^{2}\left[\alpha\left(\frac{\partial \ln x}{\partial \ln a}\right)_{T}-\frac{\ln x}{T}\right]$.

The terms, $(\ln x)$ and $(\partial \ln x / \partial \ln a)$, can be further expressed as follow (Dubinin et al., 1991)

$\ln x=-\frac{\beta E_{0}}{R T}\left[\ln \left(\frac{W_{0}}{a \tilde{v}}\right)\right]^{1 / n}$.

Taking partial differentiation of $x$ by $a$, one has

$\frac{\partial \ln x}{\partial \ln a}=\frac{\beta E_{0}}{R T n}\left[\ln \left(\frac{W_{0}}{a \tilde{v}}\right)\right]^{(1 / n)-1}$.

By substituting Eqs. (15) and (16) into Eq. (14), it yields the following expression

$q^{\text {net }}=\beta E_{0}\left\{\frac{\alpha T}{n}\left[\ln \left(\frac{W_{0}}{a \tilde{v}}\right)\right]^{(1 / n)-1}+\left[\ln \left(\frac{W_{0}}{a \tilde{v}}\right)\right]^{1 / n}\right\}$

where $\theta$ is the filling degree of the micropore, that is, $W_{0} / a \tilde{v}=\theta, \Delta H_{\text {con }}$ is the enthalpy of condensation, $\alpha$ is the thermal expansion coefficient, $a$ is the number of moles adsorbed and $\tilde{v}$ is the molar volume of adsorbed material.

Note that $W_{0}$ is the total micropore volume and is related to $W$ by the Dubinin-Astokhov equation

$W=W_{0} \exp \left[-\left(\frac{\Delta G}{\beta E_{0}}\right)^{n}\right]$

where $W$ is the volume of adsorption space, $\Delta G$ the adsorption energy, $\beta$ is the affinity coefficient and $E_{0}$ is the adsorption characteristic energy, it characterizes the sorption properties (distribution function for the adsorption potential, $f(W)$ ) of the adsorbent (Ponec et al., 1974); $n$ is the constant.

By substituting $\left(W_{0} / a \tilde{v}=\theta\right)$ into Eq. (17) one has the following expression

$q^{\mathrm{net}}(T ; \theta)=\beta E_{0}\left[\left(\ln \frac{1}{\theta}\right)^{1 / n}+\frac{\alpha T}{n}\left(\ln \frac{1}{\theta}\right)^{(1 / n)-1}\right]$.

The enthalpy of immersion $\left(\Delta H_{\mathrm{i}}\right)$ of a surface such as activated carbon in organic liquids can be described by the following equation (Ponec et al., 1974; Stoeckli and Kraehenbueh, 1981):
$-\Delta H_{\mathrm{i}}(T)=\int_{0}^{1} q^{\mathrm{st}}(T ; \theta) \mathrm{d} \theta-\Delta H_{\mathrm{con}}(T)$.

By combining Eqs. (1) and (20), one has

$-\Delta H_{\mathrm{i}}(T)=\int_{0}^{1} q^{\text {net }}(T ; \theta) \mathrm{d} \theta$.

By substituting Eq. (19) into Eq. (21) and upon integration of the final equation, one has

$-\Delta H_{\mathrm{i}}=\beta E_{0} \Gamma\left(\frac{1}{n}+1\right)+\frac{\beta E_{0} \alpha T}{n} \Gamma\left(\frac{1}{n}\right)$,

where

$\Gamma\left(\frac{1}{n}\right), \Gamma\left(\frac{1}{n}+1\right):$ the Gamma function.

In the case of activated carbon, $n=2$ (Marsh and Rand, 1970; Stoeckli and Houriet, 1976; Stoeckli et al., 1980; Barton, 1987; Jankowska et al., 1991) and the following molar enthalpy of immersion is obtained

$\Delta H_{\mathrm{i}}=\frac{\beta E_{0} \sqrt{\pi}(1+\alpha T)}{2}$.

According to the potential theory, the adsorbate conduces in the adsorption space and immerses the adsorbent (Smisek and Cerny, 1970). The potential theory further assumes that, the enthalpy of adsorption, $\Delta H$, is equal to the enthalpy of immersion, $\Delta H_{\mathrm{i}}$, that is $\Delta H \cong \Delta H_{\mathrm{i}}$. With known free energy and enthalpy of adsorption, the entropy $(\Delta S)$ of adsorption can be readily obtained by the following equation

$\Delta S=\frac{\Delta H_{\mathrm{i}}-\Delta G}{T}$.

\subsection{Statistical thermodynamic method}

Based on statistical thermodynamics, it is possible to estimate the change of total entropy of adsorption. The differential entropy change, i.e., when one mole of gas at 1 atm pressure is adsorbed by a given amount of activated carbon surface with a surface coverage of $q$, involves several possible partition functions such as total translational and vibrational. Initially, the total specific translational partition function $\left(Q_{\text {tot }}\right)$ (Stoeckli et al., 1980) is

$Q_{\mathrm{tot}}=\frac{1}{a}\left[\left(\frac{2 \pi M k T}{h^{2}}\right)^{3 / 2} \tilde{V}\right]^{a}$,

where $M$ is the molecular weight, $k$ is the Boltzmann constant, $h$ is the Planck constant, $\tilde{V}$ is the specific volume of gas and $a$ is the mole of molecules adsorbed.

According to the Sterling's approximation and replacing $\tilde{V} / N$ by $k T / P$, one has the Sackur-Tetrode equation (Stoeckli et al., 1980) 
$S_{\text {trans }}^{\mathrm{g}}=R \ln \left(\frac{T^{5 / 2} M^{3 / 2}}{P}\right)-2.30$.

If the adsorption site is regarded as a two-dimensional potential box, as implied by the kinetic derivation given above, the corresponding translational entropy $\left(S_{\text {trans }}^{\mathrm{s}}\right)$ must be evaluated. The total partition function for $n$ molecules is merely $\left.\left(2 \pi M k T / h^{2}\right) \sigma^{0}\right)^{n}$, and the normal operation yield is (Adamson, 1982)

$S_{\text {trans }}^{\mathrm{s}}=R \ln \left(M T \sigma^{0}\right)+63.8$,

where $\sigma^{0}$ is the molecular cross-sectional area.

The localized adsorption is attributed to the adsorption bond. Per degree of vibrational freedom $\left(S_{\mathrm{vib}}^{\mathrm{s}}\right)$ can be obtained as follows:

$$
\begin{aligned}
S_{\mathrm{vib}}^{\mathrm{s}} & =R\left[\frac{h v^{0} / k T}{\mathrm{e}^{h v^{0} / k T}-1}-\ln \left(1-\mathrm{e}^{-h v^{0} / k T}\right)\right], \\
& \cong R\left[1-\ln \left(h v^{0} / k T\right)\right],
\end{aligned}
$$

where $1 / v^{0}\left(\tau^{0}\right)$ is the time of molecule staying on the solid surface $\left(v^{0}\right.$ is taken to be $\left.10^{12} \mathrm{~s}^{-1}\right)$.

However, in order to be consistent with the kinetic derivation of the Langmuir equation, it is necessary to assume that there is a potential box and a weak adsorption bond of $v^{0}$ corresponding to $1 / \tau^{0}$. Under these above assumptions, one has

$\Delta S_{\text {local }}^{\mathrm{ads}}=-R \ln \left(\frac{\theta}{1-\theta}\right)+S_{\text {trans }}^{\mathrm{s}}+S_{\mathrm{vib}}^{\mathrm{s}}-S_{\text {trans }}^{\mathrm{g}}$.

The values of the entropy of "localized" adsorption can be widespread depending on whether the site is viewed as equivalent to a strong adsorption bond of negligible entropy or as a potential box with a weak bond. By combining Eq. (2a) (for $\Delta G$ ) and Eq. (29) (for $\Delta S$ ), and then substituting into Eq. (24), the adsorption enthalpy can be obtained

$$
\begin{gathered}
\Delta H=-R T \ln x+\left(-R \ln \left(\frac{\theta}{1-\theta}\right)\right. \\
\left.+S_{\text {trans }}^{\mathrm{s}}+S_{\text {vib }}^{\mathrm{s}}-S_{\text {trans }}^{\mathrm{g}}\right) T .
\end{gathered}
$$

\subsection{Adsorption energy distribution}

In order to understand the adsorption energy distribution, the following procedures are followed. The overall adsorption isotherms, $\theta_{\mathrm{t}}$, can be calculated from given isotherm, $\theta_{1}$, and adsorption energy distribution function, (Cerofolini, 1974), i.e., $\chi(\epsilon)$

$\theta_{\mathrm{t}}(T ; P)=\int_{0}^{\infty} \theta_{\mathrm{l}}(T ; P ; \varepsilon) \chi_{\mathrm{c}}(\varepsilon) \mathrm{d} \varepsilon$.

Cerofolini (1974) has modified the above equation as the following
$\theta_{\mathrm{t}}(T ; P)=\int_{0}^{\infty} \chi_{\mathrm{c}}(\varepsilon) \mathrm{d} \varepsilon$

Furthermore in order to solve the above energy distribution equation analytically, the following assumption are made:

1. Adsorption isotherms follow the Dubinin-Astakhov equation, that is

$$
\theta_{\mathrm{t}}=\frac{W}{W_{0}}=\exp \left[-\left(\frac{\Delta G}{\beta E_{0}}\right)^{n}\right] \text {. }
$$

2. Local adsorption isotherms correlate with the Langmuir type without the lateral effect, that is, $\Gamma_{\mathrm{e}}=$ $\Gamma_{\mathrm{m}} K C_{\mathrm{f}} / 1+K C_{\mathrm{f}}$, where $C_{\mathrm{f}}, K, \Gamma_{\mathrm{e}}$, and $\Gamma_{\mathrm{m}}$ are equilibrium concentration of adsorbate, equilibrium constant, adsorption density and saturation adsorption density, respectively.

3. The condensation pressure $\left(p_{\mathrm{m}}\right)$ is equal to the saturation vapor pressure $\left(p_{0}\right)$, that is, $p_{\mathrm{m}}=p_{0}$.

4. The $e_{0}$ value is the condensation heat at critical point (Eq. (34)), that is,

$\Delta G=\varepsilon-\varepsilon_{0}=R T \ln \left(\frac{p_{0}}{p}\right)$.

In addition, $\varepsilon_{0}$ can also be estimated by the Riedel equation (Perry and Green, 1984)

$\varepsilon_{0}=\Delta H_{\text {vap }}=1.093 R T_{\mathrm{c}}\left(T_{\mathrm{b}} \frac{\ln \left(p_{\mathrm{c}}-1\right)}{0.930-T_{\mathrm{b}}}\right)$,

where $T_{\mathrm{c}}$ is the critical point, $T_{\mathrm{b}}$ is the boiling point and $p_{\mathrm{c}}$ is the critical pressure.

Based on the above assumptions, and the fact that the adsorption isotherms are consistent with the Dubinin-Astakhov equation, the adsorption energy distribution can be rearranged as follows

$$
\begin{aligned}
\chi_{\mathrm{c}}(\varepsilon) & =-\frac{\partial \theta_{\mathrm{t}}}{\partial \varepsilon} \\
& =n \frac{\left(\varepsilon-\varepsilon_{0}\right)^{n-1}}{\left(\beta E_{0}\right)^{n}} \exp \left\{-\left[\left(\varepsilon-\varepsilon_{0}\right) / \beta E_{0}\right]^{n}\right\} .
\end{aligned}
$$

Table 1 summaries the relevant equations needed for the calculation of thermodynamic properties of the adsorption of VOCs by activated carbon.

\section{Experimental}

\subsection{Adsorbents and adsorbates}

Activated carbon $(8 \times 30$ mesh $)$ was provided by Kowa Cosmos Company, Japan. Before experiments, the activated carbon was stored in an oven at $105^{\circ} \mathrm{C}$ for $48 \mathrm{~h}$. Activated carbon was pretreated before adsorption experiments. To each of the five 2-1 polyethylene bottles, 
Table 1

List of analysis methods for the calculation of thermodynamic parameters

\begin{tabular}{llll}
\hline Analysis methods & \multicolumn{2}{l}{ Thermodynamic parameters } & \\
\cline { 2 - 4 } & $\Delta H$ & $\Delta G$ & $\Delta S$ \\
\hline $\begin{array}{l}\text { Immersion enthalpy } \\
\text { method }\end{array}$ & $\begin{array}{l}\Delta H \cong \Delta H_{\mathrm{i}}=\frac{\beta E_{0} \sqrt{\pi}(1+\alpha T)}{2} \\
(\text { Eq. (23)) }\end{array}$ & $\begin{array}{l}\Delta G=-R T \ln x \\
\text { (Eq. (2a)) }\end{array}$ & $\begin{array}{l}\Delta S=\frac{H_{\mathrm{i}}-\Delta G}{T} \\
\text { (Eq. (24)) }\end{array}$ \\
$\begin{array}{l}\text { Statistical thermodynamic } \\
\text { method }\end{array}$ & $\begin{array}{l}\Delta H=\Delta G+T \Delta S \\
\text { (Rearranging from Eq. (24)) }\end{array}$ & $\begin{array}{l}\Delta G=-R T \ln x \\
\text { (Eq. (2a)) }\end{array}$ & $\begin{array}{l}\Delta S_{\text {local }}^{\text {ads }}=-R \cdot \ln \left(\frac{\theta}{1-\theta}\right)+S_{\text {trans }}^{\mathrm{s}}+S_{\text {vib }}^{\mathrm{s}}-S_{\text {trans }}^{\mathrm{g}} \\
\text { (Eq. (29)) }\end{array}$ \\
\hline
\end{tabular}

it was added $500 \mathrm{~g}$ activated carbon. Added $11 \mathrm{NaOH}$ solutions to each bottle to attain various $\mathrm{NaOH}$ concentrations from 1 to $5 \mathrm{M}$. The bottles containing the activated carbon sample were then placed in a rotating vibrator and mixed for $24 \mathrm{~h}$. The activated carbons, after separation from the solution by sedimentation, were dried in an oven at $105^{\circ} \mathrm{C}$ for another $48 \mathrm{~h}$. NaOHtreated activated carbon samples (250 g) were treated further with ozone at a concentration $40 \mathrm{mg} / \mathrm{l}$ and flow rate of $2.51 / \mathrm{min}$ (or $100 \mathrm{mg} / \mathrm{min}$ ) for $30 \mathrm{~min}$. A water tank was used to control the reaction temperature during treatment to below the combustion point of the activated carbon. Activated carbon samples were washed with distilled water until the concentration of sodium ion in the rinse water reached that of the distilled water. The activated carbon was then separated from the solution, filtered, dried at room temperature, and placed in a vacuum oven at $105^{\circ} \mathrm{C}$ for $48 \mathrm{~h}$. The temperature was then decreased to $30^{\circ} \mathrm{C}$ and the activated carbon was purged with nitrogen gas for three more hours. The activated carbon samples treated were divided into the following categories: untreated, ozone only, $1 \mathrm{~N} \mathrm{NaOH}$ and ozone, $2 \mathrm{~N} \mathrm{NaOH}$ and ozone, $3 \mathrm{~N} \mathrm{NaOH}$ and ozone, $4 \mathrm{~N} \mathrm{NaOH}$ and ozone, $5 \mathrm{~N} \mathrm{NaOH}$ and ozone. These activated carbon samples were designated as: $\mathrm{AC}, \mathrm{AC}\left(\mathrm{O}_{3}\right)$, $\mathrm{AC}\left(1 \mathrm{~N}-\mathrm{O}_{3}\right), \mathrm{AC}\left(2 \mathrm{~N}-\mathrm{O}_{3}\right), \mathrm{AC}\left(3 \mathrm{~N}-\mathrm{O}_{3}\right), \mathrm{AC}\left(4 \mathrm{~N}-\mathrm{O}_{3}\right)$ and $\mathrm{AC}\left(5 \mathrm{~N}-\mathrm{O}_{3}\right)$, respectively.

\subsection{Sorption experiments}

Diffusion tubes filled with liquid benzene or MEK were placed inside a temperature control tank as to generate the VOCs needed for this study. The temperature was maintained within $\pm 0.5^{\circ} \mathrm{C}$. The concentration of VOCs in the nitrogen stream was determined by gas chromatography equipped with a flame ionization detector (HP, Model 5890 II).

The activated carbon adsorbent was then dried in a vacuum oven for $24 \mathrm{~h}$ at $105^{\circ} \mathrm{C}$ and $10^{-2}-10^{-3} \mathrm{~mm} \mathrm{Hg}$. Adsorption experiments were conducted According to the following experimental procedures place activated carbon $(50 \mathrm{mg})$ sample in the electrical balance that was connected to a data Acquisition system. A flow of nitrogen gas carrying the adsorbate was then purged through the activated carbon to allow adsorption reaction to take place. The influent concentrations of benzene ranged from 372 to $2486 \mathrm{ppm}$ and those of MEK from 500 to $1470 \mathrm{ppm}$. The inflow rate of benzene and MEK vapor was maintained at $2.0 \mathrm{l} / \mathrm{min}$. In order to obtain the thermodynamic constants, three adsorbents including $\mathrm{AC}, \mathrm{AC}\left(\mathrm{O}_{3}\right), \mathrm{AC}\left(2 \mathrm{~N}-\mathrm{O}_{3}\right)$ were selected to perform the benzene and $\mathrm{MEK}$ adsorption experiments at $30^{\circ} \mathrm{C}, 70^{\circ} \mathrm{C}$ and $120^{\circ} \mathrm{C}$. The adsorption tests were repeated four times for all adsorbate concentrations.

\section{Results and discussion}

\subsection{Thermodynamic characteristics of benzene adsorption}

Table 2 summarizes the adsorption characteristic energy and enthalpy of benzene at $30^{\circ} \mathrm{C}$ for the seven activated carbons studied. The adsorption characteristic energy, $E_{0}$, immersion enthalpies, $\Delta H_{\mathrm{i}}$, adsorption free energy, $\Delta G$, and adsorption entropy, $\Delta S$, are between 17.12 and $36.86,-20.8$ and $-44.7,-11.89$ and $-16.22 \mathrm{~kJ} /$ mole, and -29.4 and $-94.0 \mathrm{~J} / \mathrm{mole} / \mathrm{K}$, respectively. The adsorption characteristics energy, $E_{0}$, follows the order: $\mathrm{AC}\left(1 \mathrm{~N}-\mathrm{O}_{3}\right)>\mathrm{AC}>\mathrm{AC}\left(3 \mathrm{~N}-\mathrm{O}_{3}\right)>\mathrm{AC}\left(4 \mathrm{~N}-\mathrm{O}_{3}\right)>$ $\mathrm{AC}\left(\mathrm{O}_{3}\right)>\mathrm{AC}\left(5 \mathrm{~N}-\mathrm{O}_{3}\right)>\mathrm{AC}\left(2 \mathrm{~N}-\mathrm{O}_{3}\right)$. The immersion enthalpy, $\Delta_{i}$, free energy of adsorption, $\Delta G$, and entropy of adsorption, $\Delta S$ follow the order: $\mathrm{AC}(2 \mathrm{~N}-$ $\left.\mathrm{O}_{3}\right)>\mathrm{AC}\left(5 \mathrm{~N}-\mathrm{O}_{3}\right)>\mathrm{AC}\left(\mathrm{O}_{3}\right)>\mathrm{AC}\left(4 \mathrm{~N}-\mathrm{O}_{3}\right)>\mathrm{AC}(3 \mathrm{~N}-$ $\left.\mathrm{O}_{3}\right)>\mathrm{AC}>\mathrm{AC}\left(1 \mathrm{~N}-\mathrm{O}_{3}\right)$.

According to the volume filling of micropores theory, the smaller the $E_{0}$ the easier is for the adsorbates to adsorb onto the adsorbent (Ponec et al., 1974). Hu and Vansant (1995) used elutrilithe-producing carbon to adsorb benzene, and reported on adsorption characteristic energy in the range $9.8-25.9 \mathrm{~kJ} / \mathrm{mole}$. The pore structure of the activated carbon changes upon $\mathrm{NaOH}-$ ozone treatment. As a results benzene easily becomes adsorbed onto the $\mathrm{NaOH}$-ozone activated carbons. 
Table 2

Adsorption energy of benzene $(N=4)$

\begin{tabular}{llllllll}
\hline Adsorbents & $\begin{array}{l}E_{0} \\
(\mathrm{~kJ} / \mathrm{mole})^{\mathrm{a}}\end{array}$ & $\begin{array}{l}E_{0} / T \\
(\mathrm{~kJ} / \mathrm{mole}-\mathrm{K})^{\mathrm{b}}\end{array}$ & $\begin{array}{l}\Delta H_{\mathrm{i}} \\
(\mathrm{kJ} / \mathrm{mole})^{\mathrm{c}}\end{array}$ & $\begin{array}{l}\Delta h_{\mathrm{i}} \\
(\mathrm{J} / \mathrm{ml} \text {-adsorbate })^{\mathrm{d}}\end{array}$ & $\begin{array}{l}\Gamma_{\mathrm{m}} \\
(\mathrm{mole} / \mathrm{Kg})^{\mathrm{e}}\end{array}$ & $\begin{array}{l}\mathrm{K} \\
\left(\mathrm{m}^{3} / \mathrm{mole}\right)^{\mathrm{f}}\end{array}$ & $\begin{array}{l}\Delta G \\
(\mathrm{~kJ} / \mathrm{mole})^{\mathrm{g}}\end{array}$ \\
\hline $\mathrm{AC}$ & 34.45 & 113.7 & -41.8 & -464.9 & 2.90 & -15.95 & 562.5 \\
$(\mathrm{~J} / \mathrm{mole}-\mathrm{K})^{\mathrm{h}}$
\end{tabular}

${ }^{\mathrm{a}} W=W_{0} \exp \left\{-\left(A / \beta E_{0}\right)^{n}\right\}, n=2$.

$\mathrm{b} a / T$

${ }^{\mathrm{c}} \Delta H_{\mathrm{i}}=\beta E_{0} \sqrt{\pi}(1+\alpha T) / 2$.

${ }^{\mathrm{d}} \Delta h_{\mathrm{i}}=\Delta H_{\mathrm{i}} /$ molar volume, the molar volume of benzene is $90.0 \mathrm{ml} / \mathrm{mole}$ at $1 \mathrm{~atm}$ and $303 \mathrm{~K}$.

${ }^{\mathrm{e}} \Gamma_{\mathrm{m}}=$ saturation adsorption capacity.

${ }^{\mathrm{f}} K=$ equilibrium constant.

${ }^{\mathrm{g}} \Delta G=-R T \ln K, R=8.314 \mathrm{~J} / \mathrm{g}-\mathrm{mole} / \mathrm{K}, T=303 \mathrm{~K}$.

${ }^{\mathrm{h}} \Delta S=\Delta H_{\mathrm{i}}-\Delta G / T$.

Table 3

Adsorption energy of MEK $(N=4)$

\begin{tabular}{|c|c|c|c|c|c|c|c|c|}
\hline Adsorbents & $\begin{array}{l}E_{0} \\
(\mathrm{~kJ} / \text { mole })^{\mathrm{a}}\end{array}$ & $\begin{array}{l}E_{0} / T \\
(\mathrm{~kJ} / \text { mole-K })^{\mathrm{b}}\end{array}$ & $\begin{array}{l}\Delta H_{\mathrm{i}} \\
(\mathrm{kJ} / \mathrm{mole})^{\mathrm{c}}\end{array}$ & $\begin{array}{l}\Delta h_{\mathrm{i}} \\
(\mathrm{J} / \text { ml-adsorbate })^{\mathrm{d}}\end{array}$ & $\begin{array}{l}\Gamma_{\mathrm{m}} \\
(\mathrm{mole} / \mathrm{Kg})^{\mathrm{e}}\end{array}$ & $\begin{array}{l}K \\
\left(\mathrm{~m}^{3} / \text { mole }\right)^{\mathrm{f}}\end{array}$ & $\begin{array}{l}\Delta G \\
(\mathrm{~kJ} / \text { mole })^{\mathrm{g}}\end{array}$ & $\begin{array}{l}\Delta S \\
(\mathrm{~J} / \text { mole-K })^{\mathrm{h}}\end{array}$ \\
\hline $\mathrm{AC}$ & 23.54 & 77.7 & -29.7 & -327.2 & 3.07 & 241.3 & -13.82 & -52.4 \\
\hline $\mathrm{AC}\left(\mathrm{O}_{3}\right)$ & 14.47 & 47.8 & -18.3 & -201.2 & 3.64 & 72.1 & -10.78 & -24.8 \\
\hline $\mathrm{AC}\left(1 \mathrm{~N}-\mathrm{O}_{3}\right)$ & 27.74 & 91.6 & -35.0 & -385.6 & 3.27 & 322.9 & -14.55 & -67.5 \\
\hline $\mathrm{AC}\left(2 \mathrm{~N}-\mathrm{O}_{3}\right)$ & 32.34 & 106.7 & -40.8 & -449.4 & 3.00 & 481.7 & -15.56 & -83.3 \\
\hline $\mathrm{AC}\left(3 \mathrm{~N}-\mathrm{O}_{3}\right)$ & 19.05 & 62.9 & -24.0 & -264.8 & 3.30 & 143.6 & -12.51 & -37.9 \\
\hline $\mathrm{AC}\left(4 \mathrm{~N}-\mathrm{O}_{3}\right)$ & 27.18 & 89.7 & -34.3 & -377.8 & 3.01 & 333.2 & -14.63 & -58.3 \\
\hline $\mathrm{AC}\left(5 \mathrm{~N}-\mathrm{O}_{3}\right)$ & 15.90 & 85.5 & -32.7 & -360.0 & 2.99 & 306.8 & -14.42 & -60.3 \\
\hline
\end{tabular}

${ }^{\mathrm{a}} W=W_{0} \exp \left\{-\left(A / \beta E_{0}\right)^{n}\right\}$.

${ }^{\mathrm{b}} a / T$

${ }^{\mathrm{c}} \Delta H_{\mathrm{i}}=\beta E_{0} \sqrt{\pi}(1+\alpha T) / 2$.

${ }^{\mathrm{d}} \Delta h_{\mathrm{i}}=\Delta H_{\mathrm{i}} /$ molar volume, the molar volume of benzene is $90.8 \mathrm{ml} / \mathrm{mole}$ at 1 atm and $303 \mathrm{~K}$

${ }^{\mathrm{e}} \Gamma_{\mathrm{m}}=$ saturation adsorption capacity.

${ }^{\mathrm{f}} K=$ equilibrium constant.

${ }^{\mathrm{g}} \Delta G=-R T \ln K, R=8.314 \mathrm{~J} / \mathrm{g}-\mathrm{mole} / \mathrm{K}, T=303 \mathrm{~K}$

${ }^{\mathrm{h}} \Delta S=\Delta H_{\mathrm{i}}-\Delta G / T$. 


\subsection{Thermodynamic characteristics of MEK adsorption}

Table 3 summaries the MEK adsorption characteristic energy, immersion enthalpy, free energy of adsorption and entropy of adsorption for seven activated carbons. The adsorption characteristic energy, $E_{0}$, immersion enthalpy, $\Delta H_{\mathrm{i}}$, free energy of adsorption, $\Delta G$, and entropy of adsorption, $\Delta S$, are between 32.24 and $14.47,-40.8$ and $-18.3,-15.56$ and $-10.78 \mathrm{~kJ} / \mathrm{mole}$ and -83.3 and $-24.8 \mathrm{~J} / \mathrm{mole} / \mathrm{K}$, respectively. The adsorption characteristic energy, $E_{0}$, follows the order: $\mathrm{AC}(2 \mathrm{~N}-$ $\left.\mathrm{O}_{3}\right)>\mathrm{AC}\left(1 \mathrm{~N}-\mathrm{O}_{3}\right)>\mathrm{AC}\left(4 \mathrm{~N}-\mathrm{O}_{3}\right)>\mathrm{AC}>\mathrm{AC}\left(3 \mathrm{~N}-\mathrm{O}_{3}\right)>$ $\mathrm{AC}\left(5 \mathrm{~N}-\mathrm{O}_{3}\right)>\mathrm{AC}\left(\mathrm{O}_{3}\right)$. The immersion enthalpy, $\Delta H_{i}$, adsorption free energy $\Delta G$, and adsorption entropy, $\Delta S$, follow the order: $\mathrm{AC}\left(\mathrm{O}_{3}\right)>\mathrm{AC}\left(5 \mathrm{~N}-\mathrm{O}_{3}\right)>\mathrm{AC}(3 \mathrm{~N}-$ $\left.\mathrm{O}_{3}\right)>\mathrm{AC}>\mathrm{AC}\left(4 \mathrm{~N}-\mathrm{O}_{3}\right)>\mathrm{AC}\left(1 \mathrm{~N}-\mathrm{O}_{3}\right)>\mathrm{AC}\left(2 \mathrm{~N}-\mathrm{O}_{3}\right)$. Results indicate that the adsorption energies of benzene were greater than those of MEK for the same activated carbon adsorbent which implies that MEK is more adsorbable than benzene by activated carbon. This can be attributed in part to the polar-nature of the both the activated carbon and the MEK. Apparently specific chemical energy plays the most important role on VOC adsorption.

\subsection{The distribution of adsorption energy}

Fig. 1 displays the distribution of adsorption energy of benzene. Note that the data points are experimentally obtained. The adsorption energy of $\mathrm{AC}\left(2 \mathrm{~N}-\mathrm{O}_{3}\right)$ and $\mathrm{AC}\left(5 \mathrm{~N}-\mathrm{O}_{3}\right)$ are identical and mostly in the range between 10 and $50 \mathrm{~kJ} /$ mole. $\mathrm{AC}, \mathrm{AC}\left(\mathrm{O}_{3}\right), \mathrm{AC}\left(1 \mathrm{~N}-\mathrm{O}_{3}\right)$, $\mathrm{AC}\left(3 \mathrm{~N}-\mathrm{O}_{3}\right)$, and $\mathrm{AC}\left(4 \mathrm{~N}-\mathrm{O}_{3}\right)$ exhibit larger adsorption energy with a broad energy distribution profile. The smaller the adsorption energy is, the sharper the energy distribution.

\subsection{Comparison of method for the determination of desorption energies}

Three adsorbents $\left(\mathrm{AC}, \mathrm{AC}\left(\mathrm{O}_{3}\right)\right.$ and $\left.\mathrm{AC}\left(2 \mathrm{~N}-\mathrm{O}_{3}\right)\right)$, two adsorbates (benzene and $\mathrm{MEK}$ ) and three adsorption temperatures $\left(30^{\circ} \mathrm{C}, 70^{\circ} \mathrm{C}\right.$, and $120^{\circ} \mathrm{C}$ were selected in the experiments. The thermodynamic information regarding the adsorption of VOCs was calculated by two different methods as described above (Table 3). Table 4 summarizes the results of thermodynamic calculations.

\subsubsection{The immersion enthalpy method}

According to the premise of the immersion enthalpy method, it is assumed that the enthalpy is equal to the heat of immersion. When the adsorption temperature increases from $30^{\circ} \mathrm{C}$ to $120^{\circ} \mathrm{C}$, the benzene immersion enthalpy decreases from -35.0 to $-30.3,-39.8$ to -34.4 $\mathrm{kJ} / \mathrm{mole}$ for $\mathrm{AC}\left(\mathrm{O}_{3}\right)$, and -40.6 to $-35.1 \mathrm{~kJ} / \mathrm{mole}$ for $\mathrm{AC}\left(2 \mathrm{~N}-\mathrm{O}_{3}\right)$, respectively. The $\mathrm{MEK}$ immersion enthalpy decrease from -44.4 to $-38.2 \mathrm{~kJ} / \mathrm{mole}$ for $\mathrm{AC}$,

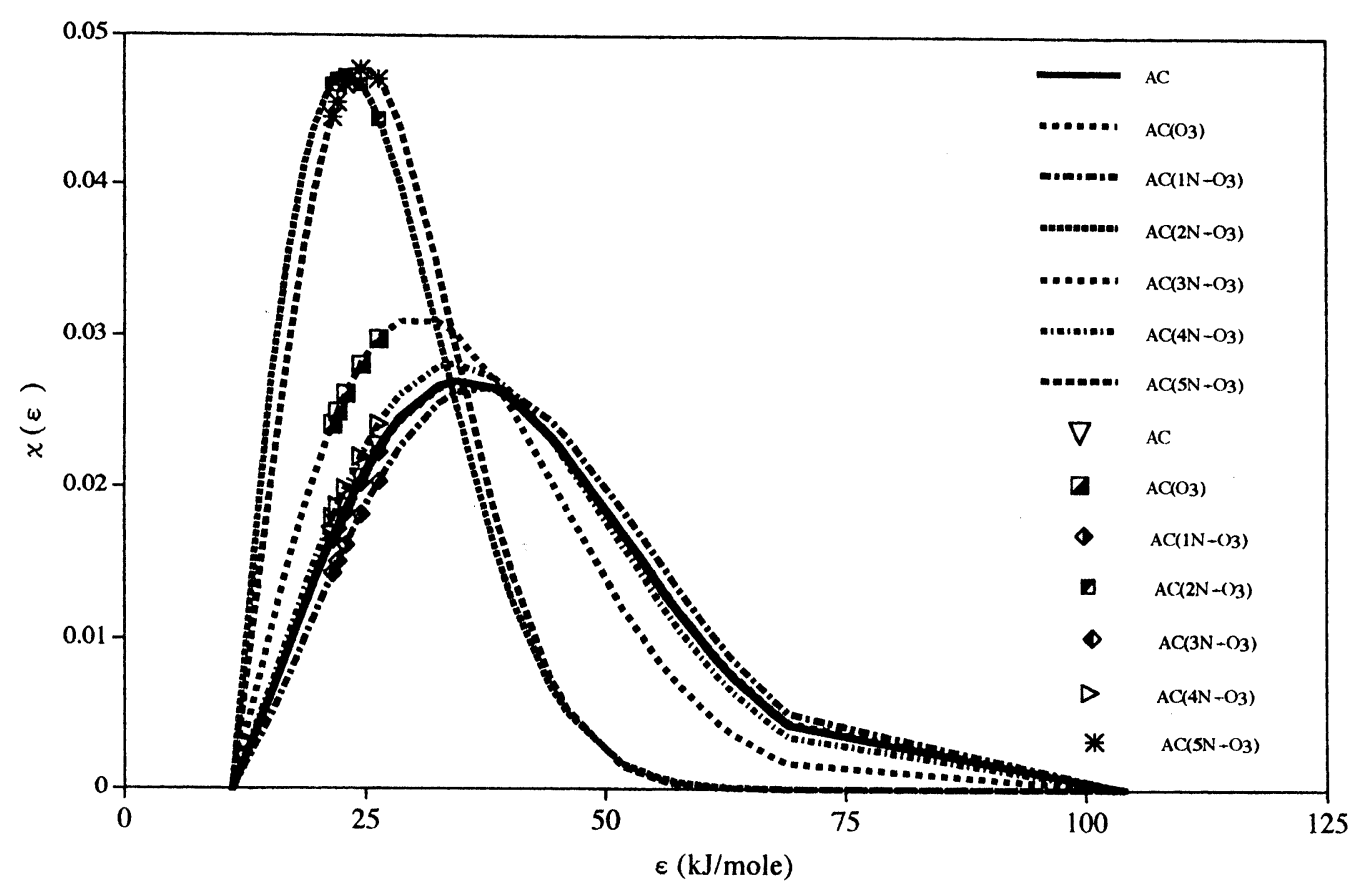

Fig. 1. Adsorption energy distribution of benzene is adsorbed on $\mathrm{AC}, \mathrm{AC}\left(\mathrm{O}_{3}\right), \mathrm{AC}\left(1 \mathrm{~N}-\mathrm{O}_{3}\right), \mathrm{AC}\left(2 \mathrm{~N}-\mathrm{O}_{3}\right), \mathrm{AC}\left(3 \mathrm{~N}-\mathrm{O}_{3}\right), \mathrm{AC}\left(4 \mathrm{~N}-\mathrm{O}_{3}\right)$, and $\mathrm{AC}\left(5 \mathrm{~N}-\mathrm{O}_{3}\right)$. The points are experimental data. The lines are fitted by Eq. (35). 


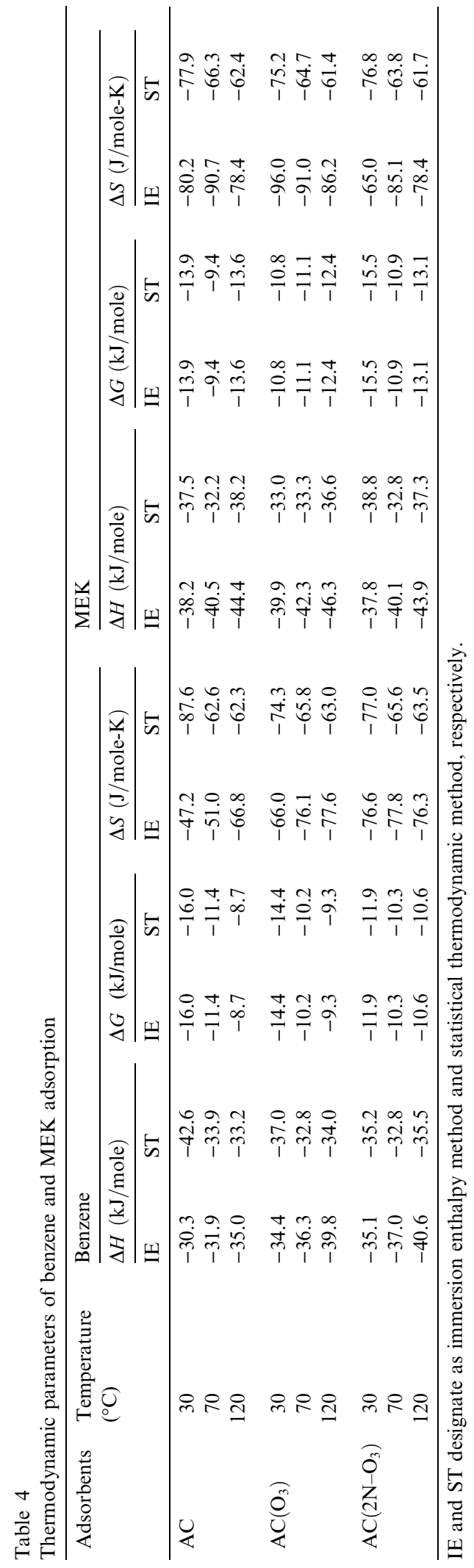

-46.3 to $-39.9 \mathrm{~kJ} / \mathrm{mole}$ for $\mathrm{AC}\left(\mathrm{O}_{3}\right)$ and -43.9 to -37.8 $\mathrm{kJ} / \mathrm{mole}$ for $\mathrm{AC},\left(2 \mathrm{~N}-\mathrm{O}_{3}\right)$, respectively.

Gibbs free energy of adsorption for benzene are between -16.0 and $-8.7 \mathrm{~kJ} / \mathrm{mole}$ for $\mathrm{AC},-14.4$ and -9.3 $\mathrm{kJ} / \mathrm{mole}$ for $\mathrm{AC}\left(\mathrm{O}_{3}\right)$, and -11.9 and $-10.6 \mathrm{~kJ} / \mathrm{mole}$ for $\mathrm{AC}\left(2 \mathrm{~N}-\mathrm{O}_{3}\right)$, respectively. Gibbs free energy of adsorption for MEK are between -13.9 and $-9.4,-12.4$ and -10.8 , and -15.5 to $-10.9 \mathrm{~kJ} / \mathrm{mole}$ for $\mathrm{AC}, \mathrm{AC}\left(\mathrm{O}_{3}\right)$, and $\mathrm{AC}\left(2 \mathrm{~N}-\mathrm{O}_{3}\right)$, respectively.

The adsorption entropy for benzene is in the range from -66.8 to $-47.2 \mathrm{~J} / \mathrm{mole} / \mathrm{K}$ for $\mathrm{AC},-77.6$ to $-66.0 \mathrm{~J} /$ mole $/ \mathrm{K}$ for $\mathrm{AC}\left(\mathrm{O}_{3}\right)$ and -76.3 to $-77.8 \mathrm{~J} / \mathrm{mole} / \mathrm{K}$ for $\mathrm{AC}\left(2 \mathrm{~N}-\mathrm{O}_{3}\right)$, respectively. MEK adsorption entropy is between -90.7 and $-78.4 \mathrm{~J} / \mathrm{mole} / \mathrm{K}$ for $\mathrm{AC},-96.0$ to $-86.2 \mathrm{~J} / \mathrm{mole} / \mathrm{K}$ for $\mathrm{AC}\left(\mathrm{O}_{3}\right)$, and -85.1 to $-65.0 \mathrm{~J} / \mathrm{mole} /$ $\mathrm{K}$ for $\mathrm{AC}\left(2 \mathrm{~N}-\mathrm{O}_{3}\right)$.

The condensation heat of benzene and MEK at normal boiling point is -30.8 and $-31.2 \mathrm{~kJ} / \mathrm{mole}$, respectively (Gallant and Yaws, 1993). Heat of benzene adsorbed on mercury is $-42.7 \mathrm{~kJ} / \mathrm{mole}$ (Ponec et al., 1974). According to the above literatures, it is noted that the adsorption energy is governed by both the VOCs and the adsorbent. The constancy of entropy of condensation at normal boiling point for benzene and MEK are -87.0 and $-88.7 \mathrm{~J} / \mathrm{mole} / \mathrm{K}$, individually (Schwarzenbach et al., 1992). Kistiakowsky utilized the Clapeyron equation and the ideal gas law to calculate the entropy of both benzene and MEK and reported a value of $-85.4 \mathrm{~J} / \mathrm{mole} / \mathrm{K}$ at normal boiling point (Schwarzenbach et al., 1992). Our results are consistent with those reported in the literature. The immersion heat of MEK is higher than that of benzene. This can be attributed to the fact that MEK has methyl and carbonyl as the major functional groups. That is, MEK is a polar species whereas benzene is non-polar. Therefore, the MEK can immerse in both the polar and non-polar sites of adsorbents and subsequently generate stronger chemical reactions than that of the benzene.

\subsubsection{Statistical thermodynamic method}

According to the principle of the statistical thermodynamic method, the major factors controlling the entropy of adsorption are the ratio of adsorption site as occupied by adsorbate, the transport of adsorbate and the vibration of the adsorbate. The vapor pressure and boiling point of benzene and MEK are close, therefore it is expected that their entropy of adsorption would be almost identical.

The enthalpy of adsorption for benzene ranges between -42.6 and $-33.2 \mathrm{~kJ} / \mathrm{mole}$ for $\mathrm{AC},-37.0$ and -32.8 $\mathrm{kJ} / \mathrm{mole}$ for $\mathrm{AC}\left(\mathrm{O}_{3}\right)$, and -38.2 to $-32.2 \mathrm{~kJ} / \mathrm{mole}$ for $\mathrm{AC}\left(2 \mathrm{~N}-\mathrm{O}_{3}\right)$, respectively. The enthalpy of adsorption for MEK is in the range between -38.2 and $-32.2 \mathrm{~kJ} /$ mole for $\mathrm{AC}-36.6$ and $-33.0 \mathrm{~kJ} / \mathrm{mole}$ for $\mathrm{AC}\left(\mathrm{O}_{3}\right)$, and -38.8 and $-32.8 \mathrm{~kJ} / \mathrm{mole}$ for $\mathrm{AC}\left(2 \mathrm{~N}-\mathrm{O}_{3}\right)$, respectively. 

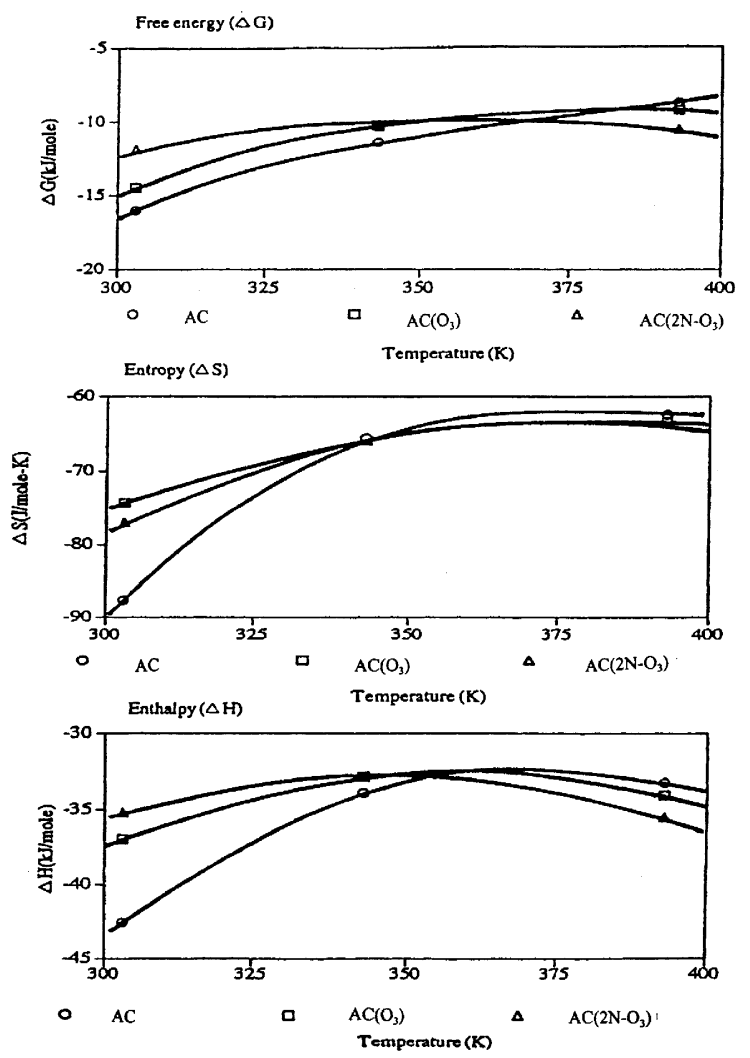

Fig. 2. The thermodynamic characteristics of benzene adsorption at differential temperatures.

Gibbs free energy of adsorption is measured by the immersion enthalpy method. The entropy of adsorption for benzene is in the range between -87.6 and $-62.3 \mathrm{~J} /$ mole/ $\mathrm{K}$ for $\mathrm{AC},-74.3$ and $-63.0 \mathrm{~J} / \mathrm{mole} / \mathrm{K}$ for $\mathrm{AC}\left(\mathrm{O}_{3}\right)$ and -77.0 and $-63.5 \mathrm{~J} / \mathrm{mole} / \mathrm{K}$ for $\mathrm{AC}\left(2 \mathrm{~N}-\mathrm{O}_{3}\right)$, respectively. The entropy of adsorption for MEK is between -77.9 and $-62.4 \mathrm{~J} / \mathrm{mole} / \mathrm{K}$ for $\mathrm{AC},-75.2$ and -61.4 $\mathrm{J} / \mathrm{mole} / \mathrm{K}$ for $\mathrm{AC}\left(\mathrm{O}_{3}\right)$ and -76.8 and $-61.7 \mathrm{~J} / \mathrm{mole} / \mathrm{K}$ for $\mathrm{AC}\left(2 \mathrm{~N}-\mathrm{O}_{3}\right)$, respectively.

Adsorption entropy and enthalpy of benzene and MEK were measured by the statistical thermodynamic method. The data are in the same range as those reported in the literatures [28-30]. Generally, the statistical thermodynamic method only deals with the physical characteristics of the adsorbate and the adsorbent. It does not consider the chemical reaction between the adsorbate and the adsorbent. This is attributed in part to the differences of the immersion enthalpy method and statistical thermodynamic method.

Figs. 2 and 3 show the variation of $\Delta G, \Delta S$ and $\Delta H$ at different temperatures. Our data are comparable with those reported by Yeh who studied the adsorption of benzene onto granular activated carbon (Everett and Ottewill, 1969). Yeh reported an adsorption enthalpy
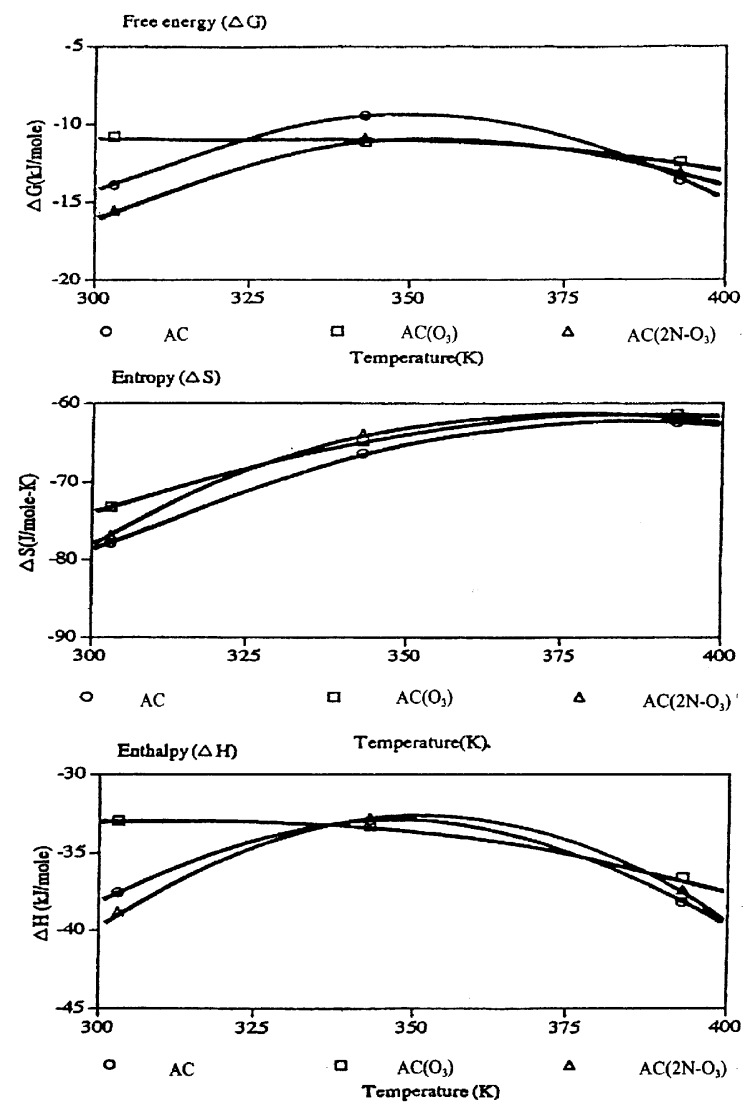

Fig. 3. The thermodynamic characteristics of MEK adsorption at differential temperatures.

between -48.1 and $-29.3 \mathrm{~kJ} / \mathrm{mole}$ (Everett and Ottewill, 1969). There is no significant difference among all thermodynamic parameters obtained by the above methods. Results clearly indicate the both methods can be used to estimate the thermodynamic parameters of VOC adsorption with equal degree of consistency.

\section{Conclusions}

This study deals with the thermodynamic parameters of the adsorption of benzene and MEK onto seven activated carbon samples. Results indicate that the adsorption energy of benzene are greater than that of MEK for the same adsorbent. Based on the energy distribution of benzene adsorption, it is concluded that the lower the adsorption energy the sharper is the energy distribution. That is, benzene is easily adsorbed by activated carbon than MEK. Both the immersion enthalpy and statistical thermodynamic methods can be used to calculate the thermodynamic parameters of adsorption at least for benzene and MEK. 


\section{References}

Adamson, A.W., 1982. Physical Chemistry of Surfaces. Wiley, New York.

Afzal, M., Mahmood, F., Saleem, M., 1993. Thermodynamics of adsorption of organic vapors on metal-loaded active carbon. Carbon 31, 757-764.

Barton, S.S., 1987. The relationship between the DubininRadushkevich parameters and the enthalpy of immersion. Carbon 25, 77-80.

Cerofolini, G.F., 1974. Localized adsorption on heterogeneous surfaces. Thin Solid Films 23, 129-152.

Cheremisinoff, P.N., Ellerbusch, F., 1978. Carbon Adsorption Handbook. Ann Arbor Science Publishers, Michigan.

Dubinin, M.M., Polyakov, N.S, Kataeva, L.I., 1991. Basic properties of equations for physical vapor adsorption in micropores of carbon adsorbents assuming a normal micropore distribution. Carbon 29, 481-488.

Everett, D.H., Ottewill, R.H., 1969. Surface area determination. In: Proceedings, International Symposium on Surface Area Determination. University of Bristol, UK.

Gallant, R.W., Yaws, C.L., 1993. Physical Properties of Hydrocarbons, vol. 2. Gulf Publishing Company, Houston.

Gregg, S.J., Sing, K.S.W., 1982. Adsorption, Surface Area, and Porosity. Academic Press, New York.

Grunewald, G.C., Drago, R.S., 1990. Oxidative dehydrogenation of ethylbenzene to styrene over carbon-based catalysis. J. Molec. Catal. 58, 227-233.

Hassan, M.M., Ruthven, D.M, Raghavan, N.S, 1987. Pressure swing air separation on a carbon molecular sieve-II. Investigation of a modified cycle with pressure equalization and no purge. Chem. Eng. Sci. 42, 2037-2043.

Hu, Z., Vansant, E.F., 1995. Chemical activation of elutrilithe producing carbon-aluminosilicate composite adsorbent. Carbon 33, 1293-1300.
Jankowska, H., Swiatkowski, A., Choma, J., 1991. Activate Carbon. Ellis Horwood, New York.

Koresh, J.E., Sofer, A., 1983. Molecular sieve carbon permselective membrance. Part I. Presentation of a new device for gas mixture separation. Sepra. Sci. Technol. 18, 723-734.

Marsh, H., Rand, B., 1970. The characterization of microporous carbons by means of the Dubinin-Radushkevich equation. J. Colloid Interface Sci. 33, 101-116.

McDowell, L., 1961. Activated carbon-loaded rayon monofilaments. J. Appl. Polymer Sci. 5, 663-667.

Perry, R.H., Green, D., 1984. Perry's Chemical Engineers' Handbook. McGraw-Hill, New York.

Ponec, V., Knor, Z., Cerny, S., 1974. Adsorption on Solids. The Chemical Rubber Company, Ohio.

Ruthven, D.M., Raghavan, N.S, Hassan, M.M., 1987. Adsorption and diffusion of nitrogen and oxygen in a carbon molecular sieve. Chem. Eng. Sci. 41, 1325-1332.

Schwarzenbach, R.P., Gschwend, P.M., Imboden, D.M., 1992. Environmental Organic Chemistry. Wiley, New York.

Smisek, M., Cerny, S., 1970. Activated Carbon: Manufacture, Properties and Applications. Elsevier, New York.

Stoeckli, H.F., Houriet, J.P., 1976. The Dubinin theory of micropore filling and the adsorption of simple molecules by active carbons over a large range of temperature. Carbon 14, 253-256.

Stoeckli, F., Perret, A., Menoa, P., 1980. Changes in micropore structure of strongly activated carbons, induced by large adsorbate molecules. Carbon 18, 443-445.

Stoeckli, H.F., Kraehenbueh, F., 1981. The enthalpies of immersion of active carbon, in relation to the Dubinin theory for the volume filling of micropores. Carbon 19, 353-356.

Trapnell, B.M.W., 1955. The parahydrogen and orthodeuterium conversions and the hydrogen-deuterium exchange. In: Emmett, P.H. (Eds), Catalysis, vol. III, Reinhold, New York, pp. 1-48. 